\title{
Effect of Omalizumab on Nasal Symptoms in Asthma and Perennial Allergic Rhinitis
}

\author{
Engin Başer ${ }^{1}$, Papatya Bayrak Degirmenci ${ }^{2}$, Ilker Burak Arslan ${ }^{1}$ and Ibrahim Cukurova ${ }^{1}$ \\ ${ }^{1}$ Department of Otorhinolaryngology, Izmir Tepecik Training and Research Hospital, Turkey \\ ${ }^{2}$ Department of Immunology, Izmir Tepecik Training and Research Hospital, Turkey
}

\begin{abstract}
Objective: To determine the efficacy of omalizumab on nasal symptoms in patients having allergic asthma with rhinitis symptoms.

Study Design: Cohort study.

Place and Duration of Study: University of Health Sciences, Izmir Tepecik Training and Research Hospital, İzmir, Turkey, between October and November 2019.

Methodology: This study included patients with perennial allergic rhinitis without nasal polyposis who were followed up in the adult allergy outpatient clinic, had findings consistent with allergic rhinitis upon nasal endoscopic examination. They were given 2-4 weekly subcutaneous omalizumab for more than six months changes in nasal symptoms were noted using nasal symptoms score. Each symptom was individually evaluated.

Results: There were 42 patients, consisting of 36 women $(85.7 \%)$ and six men (14.3\%), who received omalizumab treatment. Patient age ranged between 30 and 77 years, mean $=54.21 \pm 10.85$ years. Median change in nasal symptom score of all cases after treatment was a $3.5(2-6.25)$ decrease, which was statistically significant $(p<0.001)$. When we examine the decrease in nasal symptoms after omalizumab compared to pre-omalizumab in all cases, the most prominent change was observed in the symptom of nasal congestion.

Conclusion: Two-four weekly subcutaneous omalizumab for six months or more was effective in treating all rhinitis symptoms and had the greatest effect on nasal congestion compared to all other symptoms.
\end{abstract}

Key Words: Allergic rhinitis, Anti-IgE, Omalizumab, Total nasal symptom score (TNSS), Asthma.

How to cite this article: Başer E, Degirmenci PB, Arslan IB, Cukurova I. Effect of Omalizumab on Nasal Symptoms in Asthma and Perennial Allergic Rhinitis. J Coll Physicians Surg Pak 2020; 30(11):1170-1174.

\section{INTRODUCTION}

Allergic rhinitis (AR) is a health problem which affects the quality of life of people worldwide. ${ }^{1,2} A R$ is the inflammation of the nasal mucosa due to immunoglobulin $E$ (IgE)-mediated hypersensitivity reaction following interaction with the offending allergen. Inflammation of nasal mucosa leads to complaints and symptoms including nasal congestion, discharge, sneezing, and itching, as well as itching and conjunctivitis of the eyes. The disease usually involves the entire upper respiratory tract and conjunctiva, and sometimes the lower respiratory tract, and may be accompanied by asthma in the same person. ${ }^{2,3}$

Correspondence to: Dr. Engin Başer, Department of Otorhinolaryngology, Izmir Tepecik Training and Research Hospital, Turkey

E-mail: dr.enginbaser@hotmail.com

Received: September 02, 2020; Revised: November 05, 2020; Accepted: November 05, 2020

DOI: https://doi.org/10.29271/jcpsp.2020.11.1170

Allergic asthma is initiated by IgE-mediated immune mechanisms and is characterized by chronic inflammation of the bronchial mucosa. IgE is the main mediator that induces and maintains allergic inflammation. ${ }^{4,5}$

IgE blockers are among novel treatment modalities to relieve inhalant allergen-related clinical manifestations that are resistant to conventional treatment. ${ }^{6,7}$ Omalizumab reduces the level of free $\lg \mathrm{E}$ in serum by binding to free $\lg \mathrm{E}$. Furthermore, omalizumab is a recombinant human monoclonal antibody that inhibits effector functions of IgE by preventing IgE from binding to high-affinity receptors, without causing degranulation of effector cells, ultimately reducing early and late phase response to inhalant allergens. ${ }^{8}$ Its use in AR has been shown to reduce nasal symptoms and increase quality of life. The FDA has approved of omalizumab use in patients with severe asthma over 12 years of age, and it was shown to improve AR in these patients. Omalizumab is indicated for severe allergic asthma patients susceptible to severe and perennial allergens. ${ }^{3,9}$ Omalizumab, when used together, also increases the efficacy of immunotherapy and reduces visible side effects in perennial AR (PAR). ${ }^{10}$ Despite its efficacy in AR, it has limited use due to high cost, and rarely, risk of anaphylaxis $(0.1 \%$ of treated patients) and ana phylactoid reaction. 3,11

The aim of this study, was to determine the efficacy of omal- 
izumab on nasal symptoms and the extent of its efficacy on each nasal symptom by evaluating real-life data of patients with allergic rhinitis who were administered subcutaneous omalizumab for allergic asthma with rhinitis symptoms.

\section{METHODOLOGY}

The study was conducted at University of Health Sciences, Izmir Tepecik Training and Research Hospital, İzmir, Turkey, between October 2019 and November 2019 in 2-month period after the local Ethics Committee approval (No: 2019/12-24; Date: 07/25/2019). This study included patients with perennial allergic rhinitis without nasal polyposis who were followed up in the adult allergy outpatient clinic, who had findings consistent with allergic rhinitis upon nasal endoscopic examination before treatment, and were receiving subcutaneous omalizumab treatment for more than six months due to severe allergic asthma diagnosis (during the 10-year follow-up period, all patients (n: 42) who met the inclusion criteria and had complete medical records were included in to the study). All patients tested positive for at least one allergen in skin prick test. FEV1 (forced expiratory volume in one second) and TNSS (total nasal symptom score) of patients with house dust mite and house dust mite + mold were assessed separately according to allergen distribution.

Omalizumab dose was calculated according to prescribing information and previous clinical trials based on initial IgE level and patient weight $(0.016 \mathrm{mg} / \mathrm{kg}$ per international units $/ \mathrm{mL}$ of $\mathrm{IgE} \mathrm{per}$ month). Omalizumab was administered as subcutaneous injection once every two or four weeks. ${ }^{12,13}$

Patients receiving treatment other than omalizumab (steroid inhaler, bronchodilator inhaler, nasal steroid, antihistaminic etc.) were excluded from the study. Patients who previously underwent nasal surgery and immunotherapy were excluded from the study. Since endoscopic examinations throughout the course of treatment were subjective, they were not evaluated in ourstudy.

TNSS is a subjective test used in many studies to evaluate symptoms and treatment outcomes of patients with allergic rhinitis. ${ }^{7,14-16}$ It is used to assess the severity of nasal congestion, nasal itching, sneezing, and rhinorrhea experienced by patients in the past week. Patients are asked to score each symptom from 0 to 3 (0: no complaints; 1: mild; 2: moderate; 3: severe). Maximum possible score is 12 . This subjective tool is quick, easily applied, and well tolerated. The test may also be used to track changes that occur throughouttreatment. ${ }^{17}$

SPSS (Statistical Packages for Social Sciences, 22.0 software, Chicago, IL, USA) program wasused for statistical analyses. Qualitative variables were expressed as frequencies and percentages and quantitative as mean \pm SD and median (IQR). Shapiro-Wilk testand graphical assessments were used to testnormality distribution of quantitative data. For comparisons between two groups, Student's t-test was used to test quantitative variables with normal distribution and Mann-Whitney U-test was used to test quantitative variables without normal distribution. Paired sample t-test was used to assess comparisons of quantitative variables within groups with normal distribution. Wilcoxon signed-ranks test was used to assess comparisons of quantitative variables within groups without normal distribution. $p<0.05$ was considered statistically significant.

\section{RESULTS}

The study was conducted on 42 patients diagnosed with allergic asthma who received omalizumab treatment, consisting of 36 women $(85.7 \%)$ and six men (14.3\%). Patient age ranged between 30 and 77 years, with mean of $54.21 \pm 10.85$ years. Duration of treatment ranged between 10-120 months, mean = $46.19 \pm 28.74$. Duration of asthma was between 3-35 years. According to allergen distribution, house dust mite sensitivity was $52.4 \%$ ( $n=22$ patients), and house dust mite + mold allergen sensitivity was $47.6 \%$ ( $n=20$ patients).

Mean change in FEV1 (\%) of all cases following treatment was $12.10 \pm 4.14$ increase, which was found to be statistically significant $(p<0.001)$. Compared to pretreatment values, mean FEV1 (\%) increase was $12.27 \pm 4.32$ in house dust mite-sensitive cases and $11.90 \pm 4.03$ in mite + mold sensitive cases after treatment; these changes were found to be statistically significant $(p<0.001$, Table I).

Median change in nasal symptom score of all cases after omalizumab treatment was 3.5 (2-6.25) decrease, which was statistically significant $(p<0.001)$. There was a significant decrease in all nasal symptoms $(p<0.001)$. Median decrease in nasal symptom scorewas3.5 (1.75-6.25) units in house dust mite sensitive cases and 3.5 (2-6.5) in mite + mold sensitive cases after omalizumab compared to pretreatment values; these changes were found to be statistically significant ( $p<0.001$, Table II). The most prominent change was observed in the symptom of nasal congestion, followed by nasal discharge, while sneezing and nasal itching showed the same level of change and less change than other symptoms. In the house dust mite sensitive group, the most prominent change was observed in the symptom of nasal congestion, while changes in nasal discharge, sneezing, and nasal itching were at close levels but relatively less than nasal congestion. In the mite + mold sensitive group, the most change was observed in the symptoms of nasal congestion, while nasal discharge and sneezing decreased at close levels, nasal itching showed the least amount of change (Figure 1).

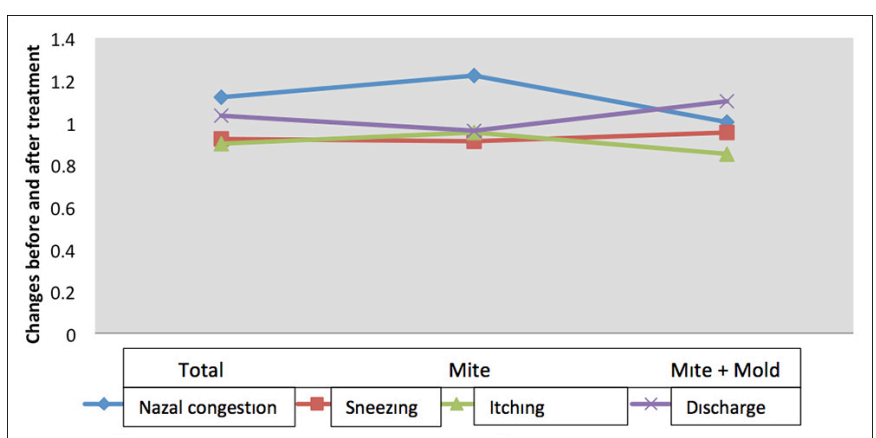

Figure 1: Distribution of nasal symptoms before and after omalizumab treatment. 
Table I: Evaluation of FEV1 (\%) before and after omalizumab treatment according to skin prick results.

\begin{tabular}{|c|c|c|c|c|}
\hline \multirow[b]{2}{*}{ FEV $1(\%)$} & \multirow[b]{2}{*}{$\begin{array}{c}\text { Total } \\
\text { Mean } \pm \text { SD }\end{array}$} & \multicolumn{2}{|c|}{ Prick result } & \multirow[b]{2}{*}{ p } \\
\hline & & Mite $(n=22)$ Mean \pm SD & $\begin{array}{c}\text { Mite }+ \text { Mold }(n=20) \\
\text { Mean } \pm \text { SD }\end{array}$ & \\
\hline Pre-omalizumab & $62.74 \pm 5.42$ & $62.82 \pm 5.40$ & $62.65 \pm 5.59$ & ${ }^{a} 0.922$ \\
\hline Post-omalizumab & $74.83 \pm 5.21$ & $75.09 \pm 5.70$ & $74.55 \pm 4.74$ & ${ }^{\mathrm{a}} 0.741$ \\
\hline Difference & $12.10 \pm 4.14$ & $12.27 \pm 4.32$ & $11.90 \pm 4.03$ & \multirow{2}{*}{${ }^{\mathrm{a}} 0.775$} \\
\hline$p$ & ${ }^{b}<0.001^{* *}$ & ${ }^{b}<0.001 * *$ & ${ }^{b}<0.001 * *$ & \\
\hline
\end{tabular}

Table II: Evaluation of nasal symptoms before and after omalizumab treatment according to prick results.

\begin{tabular}{|c|c|c|c|c|c|}
\hline & & \multirow[b]{2}{*}{$\begin{array}{c}\text { Total } \\
\text { Median (IQR) } \\
\end{array}$} & \multicolumn{2}{|c|}{ Prick result } & \multirow[b]{2}{*}{ p-values } \\
\hline & & & $\begin{array}{l}\text { Mite ( } n=22) \\
\text { Median (IQR) }\end{array}$ & $\begin{array}{c}\text { Mite }+ \text { Mold }(n=20) \\
\text { Median (IQR) }\end{array}$ & \\
\hline \multicolumn{6}{|l|}{ Nasal Congestion } \\
\hline Pre-omalizumab & Median (IQR) & $3(1.75-3)$ & $3(2-3)$ & $2(1-3)$ & $c_{0.230}$ \\
\hline Post-omalizumab & Median (IQR) & $1(1-1)$ & $1(1-1.25)$ & $1(1-1)$ & 0.622 \\
\hline \multicolumn{2}{|c|}{ Difference Median (IQR) } & $1(1-2)$ & $1(1-2)$ & $1(0.25-1.75)$ & \\
\hline & $P$ & ${ }^{d}<0.001^{* *}$ & ${ }^{d}<0.001 * *$ & ${ }^{d}<0.001^{* *}$ & ${ }^{\circ} 0.309$ \\
\hline \multicolumn{6}{|l|}{ Sneezing } \\
\hline Pre-omalizumab & Median (IQR) & $1(1-3)$ & $1.5(1-3)$ & $1(1-3)$ & 0.871 \\
\hline Post-omalizumab & Median (IQR) & $1(1-1)$ & $1(0.75-1)$ & $1(1-1)$ & 0.832 \\
\hline \multicolumn{2}{|c|}{ Difference Median (IQR) } & $1(0-2)$ & $1(0-2)$ & $1(0-2)$ & \\
\hline & $P$ & ${ }^{d}<0.001 * *$ & ${ }^{d} 0.001 * *$ & ${ }^{d} 0.001^{* *}$ & ${ }^{\circ} 0.872$ \\
\hline \multicolumn{6}{|l|}{ Itching } \\
\hline Pre-omalizumab & Median (IQR) & $1(1-3)$ & $2(1-3)$ & $1(1-2.75)$ & 0.584 \\
\hline Post-omalizumab & Median (IQR) & $1(1-1)$ & $1(0.75-1)$ & $1(1-1)$ & 0.946 \\
\hline \multicolumn{2}{|c|}{ Difference Median (IQR) } & $1(0-2)$ & $1(0-2)$ & $1(0-1.75)$ & \\
\hline & $P$ & ${ }^{d}<0.001 * *$ & ${ }^{d} 0.001^{* *}$ & ${ }^{d} 0.002 * *$ & ${ }^{\circ} 0.688$ \\
\hline \multicolumn{6}{|l|}{ Discharge } \\
\hline Pre-omalizumab & Median (IQR) & $1.5(1-3)$ & $1(1-3)$ & $2(1-3)$ & 0.644 \\
\hline Post-omalizumab & Median (IQR) & $1(0-1)$ & $1(0-1)$ & $1(0.25-1)$ & 0.936 \\
\hline \multicolumn{2}{|c|}{ Difference Median (IQR) } & $1(0-2)$ & $1(0-2)$ & $1(0.25-2)$ & \\
\hline & $P$ & ${ }^{d}<0.001 * *$ & ${ }^{d} 0.001^{* *}$ & ${ }^{d}<0.001 * *$ & ${ }^{c} 0.559$ \\
\hline \multicolumn{6}{|c|}{ Total Nasal Symptom Score } \\
\hline Pre-omalizumab & Median (IQR) & $7(5-11.25)$ & $7(5-11.25)$ & $6(5-11.25)$ & 0.645 \\
\hline Post-omalizumab & Median (IQR) & $4(2.75-4)$ & $4(2.75-4.25)$ & $4(2.5-4)$ & 0.782 \\
\hline \multicolumn{2}{|c|}{ Difference Median (IQR) } & $3.5(2-6.25)$ & $3.5(1.75-6.25)$ & $3.5(2-6.5)$ & \\
\hline & $P$ & ${ }^{d}<0.001^{* *}$ & ${ }^{d}<0.001 * *$ & ${ }^{d}<0.001 * *$ & ${ }^{\circ} 0.909$ \\
\hline
\end{tabular}

\section{DISCUSSION}

While $A R$ and asthma are among the most well-known comorbid diseases, they are closely related to epidemiological, pathophysiological, and therapeutic aspects. ${ }^{18}$ Inflammation plays a key role in the pathophysiology of both AR and asthma. ${ }^{2}$ Both diseases occur as a result of mediated inflammation of mucosa-like cells in the respiratory tract. AR and asthma have a negative impact on quality of life, labour, continuity of work, and school productivity, and lead to individual and social socioeconomic burden. ${ }^{19}$ Approximately $85 \%$ of asthma patients have $A R$, and $40 \%$ of AR patients have or will develop asthma. ${ }^{11}$

Considering mucosal resemblance and presumably overlapping dysregulation in the upper and lower respiratory tracts, coined the one airway concept, biological mechanisms that target key members of the inflammation cascade can most likely modulate the disease in various tissues. If true, a single agent with the potential to treat both the upper and lower airway will be cost-effective in the long term. ${ }^{20}$ Omalizumab plays a key role in preventing allergic inflammatory responses. Current evidence suggests that omalizumab can both significantly reduce underlying alleviation of inflammation and prevent the flare-ups that occur in patients exposed to allergens. The spectrum of events induced by anti-IgE activity on basophils, mast cells, eosinophils, and dendritic cells suggests that pharmacological actions not only inhibit immunological response via IgE mechanisms, but may also regulate $T$ cell response towards the allergen. Therefore, omalizumab has a unique mode of action comprised of 
preventing hypersensitivity and inhibiting both chronic and acute aspects of the inflammatory response in allergy. ${ }^{21}$

Omalizumab has been shown to achieve clinical benefit in patients suffering from moderate to severe allergic asthma, $A R$, and both conditions. The manner in which omalizumab exerts widespread anti-inflammatory activity across multiple systems and the visible clinical improvements in both allergic asthma and AR highlight the central role that IgE plays in such allergic disorders. ${ }^{21}$ This study investigated the effects of omalizumab on patient symptoms in PAR. Therefore, it can be used to treat symptoms that cannot be suppressed by nasal steroids and antihistamines in conventional treatment. This study is the first to demonstrate the effect of subcutaneous omalizumab on each rhinitis symptom (nasal congestion, nasal discharge, nasal itching, sneezing) while presenting real-life data.

Hanf et al. conducted a study on patients with SAR and PAR and found that patients who received omalizumab had less severe symptoms with intranasal challenge compared to the placebo group or before intervention. ${ }^{22}$ Bayar et al. indicated that omalizumab both decreased severity of nasal symptoms in $A R$ and also averted the use of other pharmacological agents. ${ }^{21}$ Chervinsky et al. conducted a placebo-controlled study on 289 patients and reported significant improvement in nasal symptom scores 4, 8, and 16 weeks after initiation of omalizumab treatment in PAR patients compared to the placebo group. ${ }^{23}$ One current review highlighted that omalizumab effectively and reliably reduced symptom scores in AR patients. ${ }^{21}$ In this study, median TNSS score was 7 (5-11.25) before omalizumab treatment and 4 (2.75-4) after treatment, indicating a significant decrease. While there was significant decrease in all rhinitis symptoms, omalizumab was most effective in reducing nasal congestion.

Omalizumab may improve nasal and bronchial symptoms in rhinitis and asthmatic patients, as well as reduce the frequency of asthma-related hospital visits. ${ }^{24}$ Omalizumab has been found to reduce all nasal symptoms and increase quality of life in adults and adolescents suffering from perennial rhinitis. ${ }^{23}$ There are also studies that show it is even more effective when applied together with allergen immunotherapy. ${ }^{25}$ Subcutaneous immunotherapy (SIT) and omalizumab combination led to higher patient satisfaction compared to patients receiving SIT alone. Omalizumab has been associated with reduced symptoms and increased quality of life in patients with uncontrolled allergic rhinosinusitis resistant to conventional treatment. ${ }^{26}$ Similarly, Kamin et al. demonstrated that omalizumab together with immunotherapy increased effectiveness of immunotherapy in PAR. ${ }^{10}$

The strongest effect of the omalizumab was observed in the symptom of nasal congestion. This may be due to the unique effect of omalizumab via preventing hypersensitivity and inhibiting both chronic and acute aspects of the inflam- matory response in allergy.

There are some limitations in this study. Due to the long duration of treatment (between 10 to 120 months), the effect of omalizumab exposure time on nasal symptom scores could not been demonstrated. Objective indices, such as nasal airway resistance or laboratory examination of IgE and other inflammatory factors could not be evaluated before and after omalizumab treatment. Endoscopic examinations were not obtained from all patients. Furthermore, patients were not separated into AR and non-AR groups.

\section{CONCLUSION}

This study demonstrated the effect of omalizumab on nasal symptoms in patients undergoing omalizumab treatment due to allergic asthma by presenting real-life data before and throughout the course of treatment and addressing its efficacy on each symptom. According to these results, omalizumab was effective in treating all rhinitis symptoms and had the greatest effect on nasal congestion compared to all other symptoms.

\section{ETHICAL APPROVAL:}

All procedures performed in studies involving human participants were in accordance with the ethical standards of the institutional and/or national research committee (include name of committee + reference number) and with the 1964 Helsinki Declaration and its later amendments or comparable ethical standards. Local Ethics Committee approval was obtained from Health Sciences University, İmir Tepecik Training and Research Hospital (No: 2019/12-24; Date: 07/25/2019).

\section{CONFLICT OF INTEREST:}

Authors declared no conflict of interest.

\section{AUTHORS' CONTRIBUTION:}

EB, PB, IBA, IC: Medical practices, concept, design, data collection or processing, analysis or interpretation, literature search, writing.

\section{REFERENCES}

1. Dogru M, Evcimik MF, Cirik AA. Is neutrophil-lymphocyte ratio associated with the severity of allergic rhinitis in children? Eur Arch Oto-Rhino-Laryngology 2016; 273 (10):3175-8. doi:10.1007/s00405-015-3819-y

2. Bousquet J, Khaltaev N, Cruz AA, Denburg J, Fokkens WJ, Togias A, et al. Allergic Rhinitis and its Impact on Asthma (ARIA) 2008. Allergy 2008; 63:8-160. doi:10.1111/j. 1398-9995.2007.01620.x

3. Ozdemir O, Elmas B. New Developments in the diagnosis and therapy of allergic rhinitis. Asthma Allergy Immunol 2017; 15(1). doi:10.21911/aai.5033.

4. Fbilgi R, Pdeğir İ. A Ğ IR allerj i k astımda 1 yıllık ant İ -IGE (omal i zumab) deney i $\mathrm{m}$ i $\mathrm{m}$ i z our antı-ıge (omalızumab) experience in severe allergıc asthma: 1st year experience 
2017; 165-171.

5. Karpel J, Massanari M, Geba GP, Kianifard F, Inhaber N, Zeldin RK. Effectiveness of omalizumab in reducing corticosteroid burden in patients with moderate to severe persistent allergic asthma. Ann Allergy Asthma Immunol 2010; 105(6):465-70. doi:10.1016/j.anai.2010.09.011.

6. Unsel M, Hospital MI, Gokmen N. An adult-onset egg allergy. 2015; (January 2013).

7. Cingi C, Kayabasoglu G, Nacar A. Update on the medical treatment of allergic rhinitis. Inflamm Allergy Drug Targets 2009; 8(2):96-103. doi: 10.2174/187152809788462653.

8. D'Amato G. Role of anti-IgE monoclonal antibody (omalizumab) in the treatment of bronchial asthma and allergic respiratory diseases. Eur J Pharmacol 2006; 533(1-3):302-307. doi:10.1016/J.EJPHAR.2005.12.045

9. Bousquet J, Van Cauwenberge P, Aït Khaled N, Bachert C, Baena-Cagnani, CE, Bouchard J, et al. Pharmacologic and anti-IgE treatment of allergic rhinitis ARIA update (in collaboration with GA2LEN). Allergy Eur J Allergy Clin Immunol 2006; 61(9):1086-96. doi:10.1111/j.1398-9995.2006. 01144.x

10. Kamin W, Kopp MV, Erdnuess F, Schauer U, Zielen S, Wahn $U$. Safety of anti-IgE treatment with omalizumab in children with seasonal allergic rhinitis undergoing specific immunotherapy simultaneously. Pediatr Allergy Immunol 2010; 21(1 Pt 2):e160-5. doi:10.1111/j.1399-3038.2009.00900.x

11. Bousquet J, Van Cauwenberge P, Khaltaev N, Aria Workshop Group, World Health Organization. Allergic rhinitis and its impact on asthma. J Allergy Clin Immunol 2001; 108(5 Suppl):S147-334. doi:10.1067/mai.2001.118891.

12. Bavbek S, Aydin Ö, Kepil Özdemir S, Yılmaz I, Celik GE, Demirel YS, et al. Ağır Allerjik Astımlı Hastalarda Anti-ıgE (Omalizumab) Tedavisi. Tuberk Toraks 2010; 58(4):425-34.

13. Barnes PJ. Anti-IgE therapy in asthma: Rationale and therapeutic potential. Int Arch Allergy Immunol 2000; 123(3):196-204. doi:10.1159/000024444.

14. Hermelingmeier KE, Weber RK, Hellmich M, Heubach CP, Mösges R. Nasal irrigation as an adjunctive treatment in allergic rhinitis: A systematic review and meta-analysis. Am J Rhinol Allergy 2012; 26(5):119-25. doi:10.2500/ajra. 2012.26.3787.

15. Sansila K, Eiamprapai P, Sawangjit R. Effects of self-prepared hypertonic nasal saline irrigation in allergic rhinitis: $A$ randomised controlled trial. Asian Pacific J allergy Immunol 2018; 38(3):200-7. doi:10.12932/AP-090618- 0331.

16. Boulay ME, Boulet LP. The rhinitis control scoring system: Development and validation. Am J Rhinol Allergy 2016; 30(1):54-9. doi:10.2500/ajra.2016.30.4260.

17. Meltzer EO. Evaluating rhinitis: clinical, rhinomanometric, and cytologic assessments. J Allergy Clin Immunol 1988; 82(5 Pt 2):900-8. doi: 10.1016/0091-6749(88)90032-2.

18. Navarro A, Valero A, Juliá B, Quirce S. Coexistence of asthma and allergic rhinitis in adult patients attending allergy clinics: ONEAIR study. J Investig Allergol Clin Immunol 2008; 18(4):233-8.

19. Gaugris S, Sazonov-Kocevar V, Thomas M. Burden of concomitant allergic rhinitis in adults with asthma. J Asthma 2006; 43(1):1-7. doi:10.1080/027709005004 46823.

20. Kariyawasam HH, Robinson DS, Lund VJ, Rennie C, Bidder T, Sahota J. Omalizumab treats chronic rhinosinusitis with nasal polyps and asthma together-a real life study. Rhinol J. 2018; 56(1):42-5. doi:10.4193/rhin17.139.

21. Bayar Muluk N, Bafaqeeh SA, Cingi C. Anti-IgE treatment in allergic rhinitis. Int J Pediatr Otorhinolaryngol 2019; 127:109674. doi:10.1016/j.ijporl.2019.109674

22. Hanf G, Noga O, O'Connor A, Kunkel G. Omalizumab inhibits allergen challenge-induced nasal response. Eur Respir J 2004; 23(3):414-8. doi:10.1183/09031936. 04.00024504.

23. Chervinsky P, Casale T, Townley R, Tripathy I, Hedgecock S, Shen $\mathrm{H}$, et al. Omalizumab, an anti-IgE antibody, in the treatment of adults and adolescents with perennial allergic rhinitis. Ann Allergy, Asthma Immunol 2003; 91(2):160-7. doi:10.1016/S1081-1206(10)62171-0.

24. Vignola AM, Humbert M, Bousquet J, Boulet LP, Hedgecock $\mathrm{S}$, Blogg $\mathrm{M}$, et al. Efficacy and tolerability of anti-immunoglobulin $E$ therapy with omalizumab in patients with concomitant allergic asthma and persistent allergic rhinitis: SOLAR. Allergy 2004; 59(7):709-17. doi:10.1111/ j.1398-9995.2004.00550.x

25. Şimşek Y, Yılmaz Ö, Yüksel H. Allerjik Rinit. Asthma Allergy Immunol 2018; (10). doi:10.21911/aai.373.

26. Tsabouri S, Tseretopoulou X, Priftis K, Ntzani EE. Omalizumab for the treatment of inadequately controlled allergic rhinitis: A Systematic review and meta-analysis of randomized clinical trials. J Allergy Clin Immunol Pract 2014; 2(3):332-40.e1. doi:10.1016/j.jaip.2014.02.001. 